\title{
Effect of Organic Additives on Synthesis and Characterization of Nano Crystalline Strontium Malonate
}

\author{
E.A. Abdel-Aal ${ }^{1}$, A.N. El-Shazly ${ }^{1}$ and M.F. El-Shahat ${ }^{2}$ \\ 1 Central Metallurgical Research \& Development Institute (CMRDI), \\ P.O. Box: 87 Helwan, Cairo, Egypt \\ 2 Ain Shams University, Faculty of Science, Cairo, Egypt \\ E-mail Address: eabde@Yahoo.com \& sayedabdelaal@cmrdi.sci.eg
}

A basic study was carried out to synthesis of nano crystalline strontium malonate and to understand the crystallization of strontium malonate without and with addition of sodium dodecyl sulfate surfactant (SDS) and poly ethylene glycol (PEG). Induction time was measured under different supersaturations ranging from 2.6 to 4.3. This is the time elapsed between the achievement of supersaturation and the appearance of a solid phase. The results show that, the induction time decreases exponentially with increasing the Supersaturation. On the other hand, the induction time is decreased with addition of SDS and PEG. Interestingly, with addition of the SDS and PEG, the agglomerated samples are investigated by using Scanning Electron Microscopy (SEM) investigation, the crystalline sizes of the formed crystals without and with SDS and PEG are 244 $\mathrm{nm}, 222 \mathrm{~nm}$ and $121 \mathrm{~nm}$, respectively.

\section{Introduction:}

Alkaline earth metals and alkali metals are almost invariably found in an oxidized state as a component of metallo-organic salts due to the highly reactive nature of such elements. Salts of such metal-ions are widely distributed throughout nature. Strontium is one of the less common of these elements, but is an important component of some salts due to the beneficial actions of strontium in biological systems [1].

They are used in a great number of industrial processes and in production of food products, medical products, pharmaceutical ingredients, vitamins and other health related products, products for personal care, as well as for a number of industrial products such as fertilizers, building materials, catalysts, ceramics, glass, iron and steel manufacture and in a great number of other products [1]. 
Organic additives play an important role in crystallization. They alter the surface properties of the crystals. In addition, the additives change nucleation, growth, shape of the crystals and their agglomeration or dispersion behavior. Surfactants can either enhance or retard crystallization. The reported mechanism for enhancing growth of crystals is that surfactant increases the localized supersaturation around the crystals. So, faster growth will occurred [2-8].

The main objective of this work is to study the crystallization of strontium malonate and the effect of additives such as sodium dodecyl sulfate (SDS) and poly ethylene glycol (PEG) on the induction time and nucleation of the formed crystals in aqueous medium. Surface energy, nucleation rate, free energy and critical nucleus size with and without additives were calculated and compared.

\section{Experimental:}

\subsection{Chemicals and Solutions:}

Pure chemicals including malonic acid $\left[\mathrm{CH}_{2}(\mathrm{COOH})_{2}\right]$ from MERCK Company and strontium carbonate anhydrous $\left[\mathrm{SrCO}_{3}\right]$ from Oxford Company are used for this study. In addition, SDS (sodium dodecyl sulfate) surfactant $\left[\mathrm{C}_{12} \mathrm{H}_{25} \mathrm{SO}_{4}{ }^{-} \mathrm{Na}^{+}\right]$and poly ethylene glycol (PEG) with low molecular weight 400 $\left[\mathrm{H}\left(\mathrm{OCH}_{2} \mathrm{CH}_{2}\right)_{\mathrm{n}} \mathrm{OH}\right]$ from Fisher Scientific Company and Fluka Company are used.

\subsection{Preparation of Strontium Malonate:}

Malonic acid solution of concentration (1.25- $2.5 \%)(90 \mathrm{ml})$ with $10 \mathrm{ml}$ of water or water/additive solution was added in $500-\mathrm{ml}$ beaker and heated to $45^{\circ} \mathrm{C}$ using a water bath. Then, the $\mathrm{SrCO}_{3}$ of concentration (2.1-3.55\%) $(90 \mathrm{ml})$ of deionized water of the same temperature was added simultaneously with $10 \mathrm{ml}$ of water or water/additive solution of the same temperature. The reaction was kept at $45^{\circ} \mathrm{C}$ with constant agitation. The conductivity of the resulting solution is measured at different time intervals during the course of the reaction. A graph of time vs. conductivity was plotted. The time corresponding to the point of intersection of the two asymptotic lines represents the induction time.

\section{Results and Discussion:}

Strontium malonate was prepared according to the following reaction equation:

$$
\mathrm{SrCO}_{3}+\mathrm{CH}_{2}(\mathrm{COOH})_{2} \quad \ddagger \quad \mathrm{Sr}(\mathrm{COO})_{2} \mathrm{CH}_{2}+\mathrm{CO}_{2}+\mathrm{H}_{2} \mathrm{O}
$$


The strontium malonate crystals grow at $45^{\circ} \mathrm{C}$ in malonic acid and strontium carbonate solution with and without additive. The experiments are performed at different supersaturation. The Supersaturation (S) was calculated [9] as follows:

$$
\text { Supersaturation }(\mathbf{S})=\mathbf{c}-\mathbf{c}^{*}
$$

where:

c: Strontium malonate concentration, \%

$\mathrm{c}^{*}$ : Strontium malonate (solute) solubility under the applied conditions $=0.141 \mathrm{~g} / 100 \mathrm{ml}$ water $=0.141 \%[10]$.

The results of conductivity and induction time measurements are presented in Table (1).

Effect of supersaturation on induction time with and without additives

Effects of crystallization times on conductivity at different supersaturations with and without additive are studied. Example of the results is given in Fig. 1. The conductivity of malonic acid solution of $2 \%$ concentration, strontium carbonate suspension of $2.8 \%$ concentration, SDS solution, PEG solution and bi-distilled water are $8.6 \mathrm{mS} / \mathrm{cm}, 7.25 \mathrm{mS} / \mathrm{cm}, 3.3 \mathrm{mS} / \mathrm{cm}, 0.5$ $\mathrm{mS} / \mathrm{cm}$ and $0.25 \mathrm{mS} / \mathrm{cm}$ respectively. So the initial conductivity of baseline is lower than that with additive solution as shown in (Fig. 1).

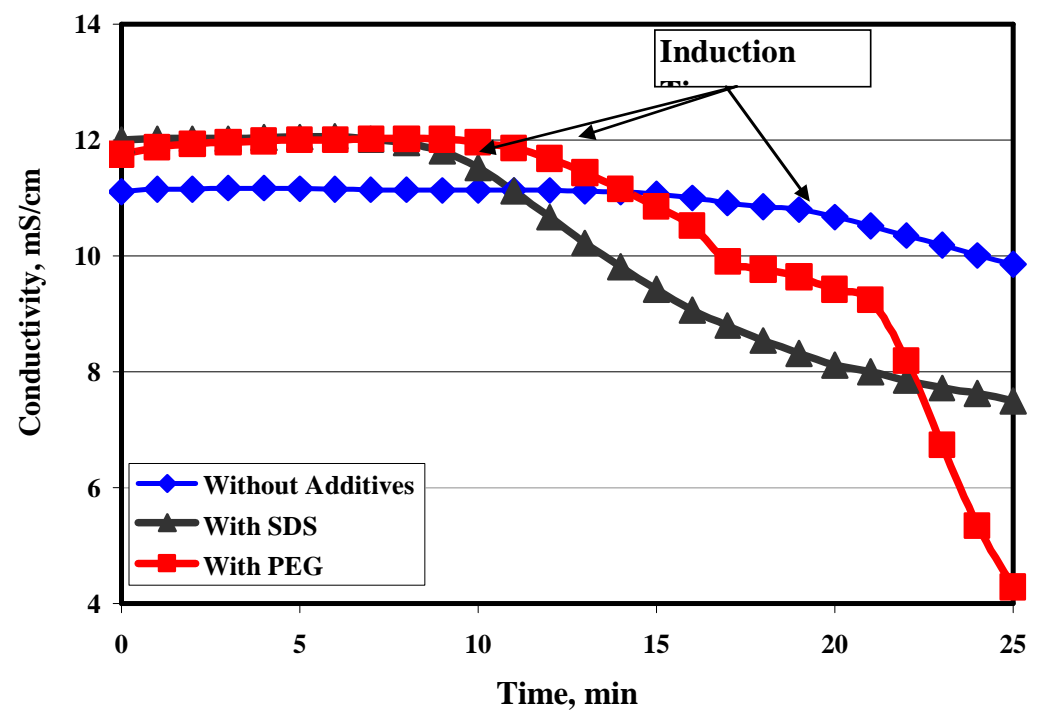

Fig. (1): Effect of Crystallization Time on conductivity at Supersaturation 3.4 with and without Additives 
Moreover, induction times were determined at different supersaturation with and without additives and given in Table (1). These results confirm that 100 ppm SDS surfactant or $100 \mathrm{ppm}$ PEG polymer consistently decrease the induction time to a lower degree than the without additives at all the studied supersaturation. In all these cases, as the supersaturation has increased, the induction time is decreased.

The decrease in the measured conductivity may be due to the decrease in moumber of ionized salt and formation of strontium malonate which is non conductive material.

Table (1): Effect of additives on the Induction Time (T) of Strontium malonate (At Different Supersaturation)

\begin{tabular}{||l|c|c|c|c||}
\hline \multirow{2}{*}{\multicolumn{1}{|c|}{ Item }} & \multicolumn{4}{|c||}{ Supersaturation } \\
\cline { 2 - 5 } & 4.3 & 3.4 & 3.0 & 2.6 \\
\cline { 2 - 5 } & $\mathrm{t}^{*}$ & $\mathrm{t}$ & $\mathrm{t}$ & $\mathrm{t}$ \\
\hline Without Additives & 8.2 & 16.8 & 18.2 & 37 \\
\hline With 100 ppm SDS Surfactant & 6.4 & 9.6 & 12.8 & 22 \\
\hline With 100 ppm PEG Polymer & 7.6 & 11.2 & 12 & 14.4 \\
\hline
\end{tabular}

$*$ in minutes

\section{Correlation between supersaturation and induction time:}

\subsection{Surface Energy $(\gamma)$ Calculation:}

The surface energy (interfacial tension) between the crystals and the aqueous solution is a fundamental parameter for understanding the rate of both nucleation and crystal growth. Based on the classic homogenous nucleation theory, the induction time can be related to the supersaturation using the following correlation $[11,12]$ :

$$
\log \left(t_{\text {ind }}\right)=A+\frac{B}{T^{3}\left(\log ^{2} S\right)}
$$

Where $\mathbf{A}$ is an empirical constant (dimensionless), $\mathbf{T}$ is the absolute temperature $\left({ }^{\circ} \mathrm{K}\right)$ and $\mathbf{B}$ depends on the number of variables, and is given by:

$$
B=\frac{\beta \gamma^{3} V_{m}^{2} N_{A} f(\theta)}{(2.3 R)^{3}}
$$


where $\boldsymbol{\beta}$ is a geometric (shape) factor of $16 \pi / 3$ for the spherical nucleus, $\boldsymbol{f}(\boldsymbol{\theta})$ is a correction factor, when purely homogeneous nucleation takes place $f(\theta)=1$ and when heterogeneous nucleation occurs $f(\theta)=0.01, \mathbf{V}_{\mathbf{m}}$ is the molar volume (which is calculated by molecular weight/ density and found to be $141.5 \mathrm{~cm}^{3}$ $\left.\mathrm{mol}^{-1}\right)$ and $\mathbf{R}$ is the gas constant $\left(\mathrm{J} / \mathrm{mol}{ }^{\circ} \mathrm{K}\right), \boldsymbol{\gamma}$ is the surface energy $\left(\mathrm{J} / \mathrm{m}^{2}\right), \mathbf{N}_{\mathbf{A}}$ is the Avogadro's number $\left(\mathrm{mol}^{-1}\right)$. Plotting of $\log \mathrm{t}_{\text {ind }}$ against $1 /\left[\log ^{2} \mathrm{~S}\right]$ over a range of high supersaturation ratios (2.6-4.3) for a fixed temperature gives a straight line with slope (B), relative to homogenous nucleation. As a matter of fact, the change of nucleation mechanism produces change in the slope of $\mathbf{B}[11,12]$.

Relation between $\log$ induction time and $1 / \log ^{2}$ supersaturation with and without $100 \mathrm{ppm}$ additive is given in Fig. (2). The calculated surface energies are $5.95,5.66$ and $4.46 \mathrm{~mJ} / \mathrm{m}^{2}$ without, with SDS or PEG, respectively. It is clear that, the surface energy is decreased with addition of SDS or PEG. Decreasing the surface energy leads to increasing the nucleation rate of strontium malonate crystals $[2,14]$. Generally, the surface energy for more soluble salts is less than that for less or sparingly soluble salts $[2,14]$ as shown by the following calculations:

\section{Calculation of Nucleation Rate $(\mathbf{J s})$, Free Energy Change $\left(\Delta \mathbf{G}_{\mathrm{cr}}\right)$ and Critical Nucleus Radius (r)}

Based on classic homogenous nucleation, it can easily calculate the nucleation rate, i.e., the number of nuclei formed per unit time per volume by applying the following relation [9]:

$$
J s=F \exp \left[\frac{-\beta \gamma^{3} V_{m}^{2} N_{A} f(\theta)}{(R T)^{3} \ln ^{2} S}\right]
$$

Where $\mathbf{J} \mathbf{s}$ is the nucleation rate and $\mathbf{F}$ is a frequency constant and is known as the pre-exponential factor and has a theoretical value of $10^{30}$ nuclei $/ \mathrm{cm}^{3} . \sec [13]$. By knowing the surface energy of strontium malonate crystals $(\gamma)$, it can easily determine the nucleation rate with and without additive. The difficulty with applying the above equation is that it predicts the nucleation rate only at high supersaturation [9]. So, it is applied at supersaturation ranged from 2.6 to 4.3. The free energy change $\Delta \mathrm{G}_{\mathrm{cr}}$ for the formation of critical nucleus size can be calculated from the following Arrhenius type equation [9, 13 and 15]:

$$
\mathbf{J s}=\mathbf{F} \exp \left[-\Delta \mathbf{G}_{\mathrm{cr}} / \mathrm{KT}\right]
$$

Where $\mathbf{K}$ is Boltzman constant and $\mathbf{T}$ is the absolute temperature. 


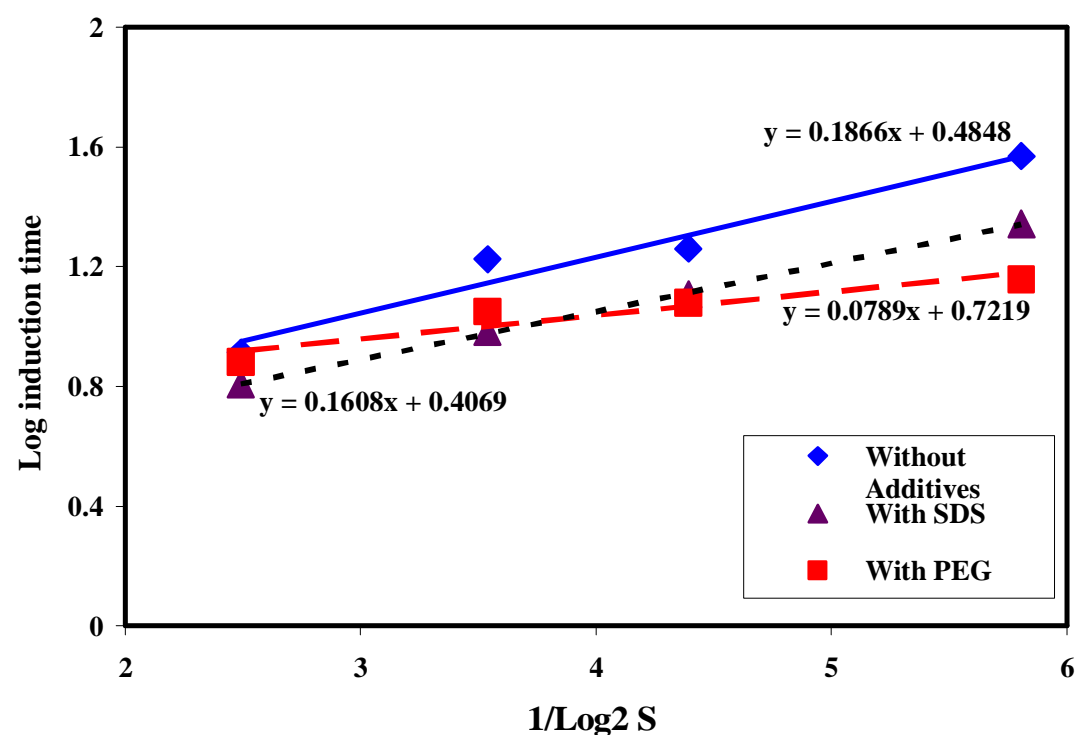

Fig. (2): Relation between Log Induction Time and $1 / \log ^{2}$ Supersaturation with and without Additives

By known the free energy change $\left(\Delta \mathrm{G}_{\mathrm{cr}}\right)$, the radius of the spherical critical nucleus ( $r$ ) can be calculated from the following equation:

$$
\Delta G_{c r}=4 / 3 \pi r^{2} \gamma
$$

The number of molecules in the critical nucleus can be calculated as the following equation [21]:

$$
i=4 \pi r^{3} N_{A} / 3 V_{m}
$$

Table (2) and Figs. ( $3 \& 4$ ) show nucleation rate, free energy change for formation of critical nucleus size and radius of critical nucleus of strontium malonate crystals with and without additive at supersaturation ranged from 2.6 to 4.3. It is clear that, addition of SDS surfactant or PEG polymer increases the nucleation rate at all the studied supersaturation compared with without additives. High nucleation rate means that a high number of formed nuclei are obtained. These nuclei have relatively lower chance to grow to large crystals compared to lower number of formed nuclei grows under the same conditions. The nucleation rates at supersaturation of 3.4 are $2.35 \times 10^{29}, 2.88 \times 10^{29}$ and $5.44 \times 10^{29}$ nuclei/cm.sec without and with $100 \mathrm{ppm}$ SDS or $100 \mathrm{ppm}$ PEG polymer addition, respectively. 
Table (2): Effect of additives on Nucleation Rate, Free Energy Change for Formation of Critical Nucleus Size of Strontium Malonate Crystals (At Different Supersaturations)

\begin{tabular}{|c|c|c|c|c|c|c||}
\hline \hline \multirow{3}{*}{ Supersaturation } & \multicolumn{4}{|c|}{$\begin{array}{c}\text { Nucleation Rate, } \\
\text { nuclei/cm }{ }^{3} \text {.sec } \times 10^{29}\end{array}$} & \multicolumn{2}{c||}{$\begin{array}{c}\text { Formation of Critical } \\
\text { Nucleus Size } \\
\Delta \mathbf{G}_{\text {cr }} \times 1^{-21}, \text { Joule }\end{array}$} \\
\cline { 2 - 8 } & $\begin{array}{c}\text { Without } \\
\text { Additives }\end{array}$ & $\begin{array}{c}\text { With } \\
\text { SDS }\end{array}$ & $\begin{array}{c}\text { With } \\
\text { PEG }\end{array}$ & $\begin{array}{c}\text { Without } \\
\text { Additives }\end{array}$ & $\begin{array}{c}\text { With } \\
\text { SDS }\end{array}$ & $\begin{array}{c}\text { With } \\
\text { PEG }\end{array}$ \\
\hline 2.6 & 0.83 & 1.17 & 3.51 & 10.9 & 9.38 & 4.59 \\
\hline 3.0 & 1.52 & 1.98 & 4.53 & 8.24 & 7.09 & 3.47 \\
\hline 3.4 & 2.35 & 2.88 & 5.44 & 6.33 & 5.46 & 2.67 \\
\hline 4.3 & 3.44 & 3.99 & 6.38 & 4.67 & 4.02 & 1.97 \\
\hline
\end{tabular}

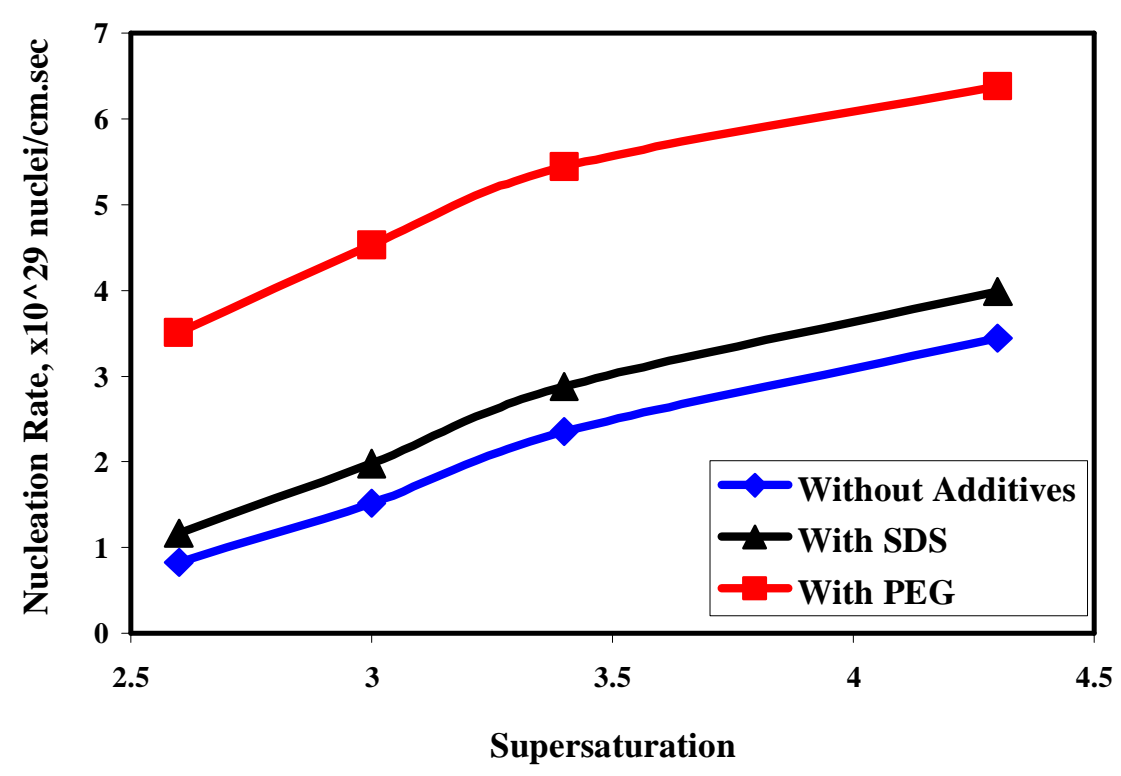

Fig. (3): Effect of Supersaturation on the nucleation rate with and without Additives

The free energy change for formation of critical nucleus size is decreased with increasing the supersaturation. It is also decreased with addition of additives. In parallel, the radius of critical nucleus is decreased with increasing the supersaturation and/or with addition of additives Fig. (4) and Table (3). 


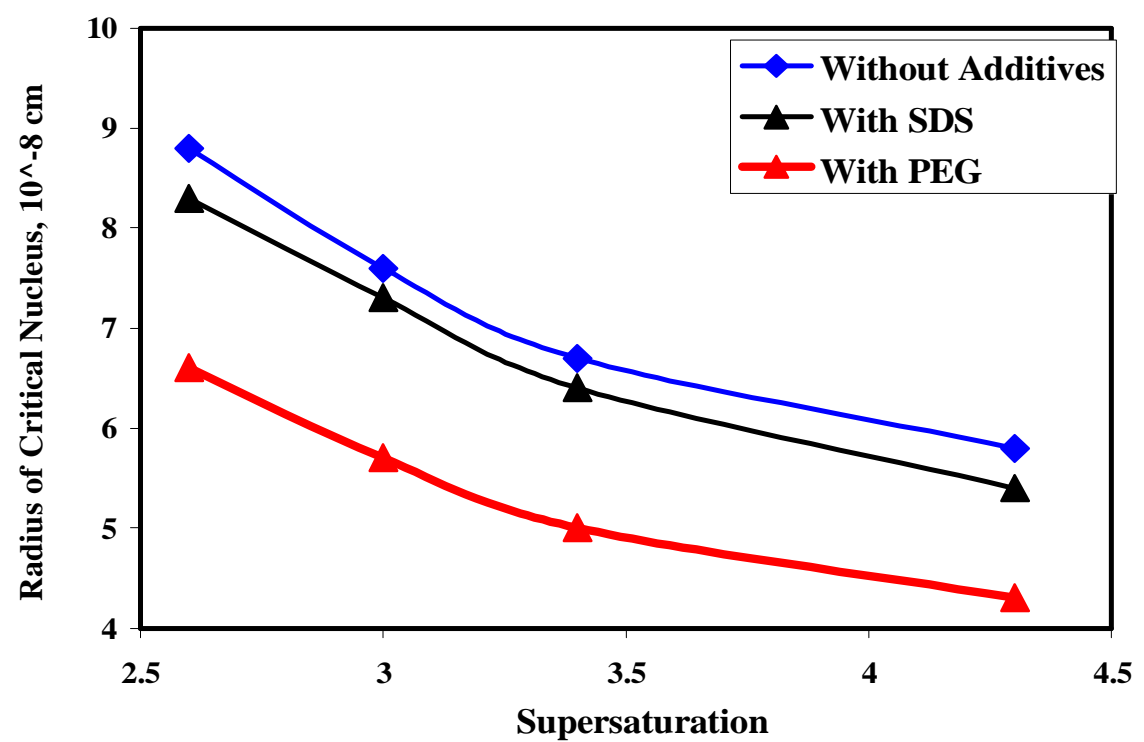

Fig. (4): Effect of Supersaturation on the Radius of Nucleus with and without Additives.

Table (3): Effect of additives on Radius of critical nucleus and Number of Molecules in the critical nucleus (At Different Supersaturation)

\begin{tabular}{||c|c|c|c|c|c|c||}
\hline \multirow{2}{*}{ Supersaturation } & \multicolumn{3}{|c|}{$\begin{array}{c}\text { Radius of Critical Nucleus, } \\
\text { cm } 1^{-8}\end{array}$} & \multicolumn{3}{c|}{$\begin{array}{c}\text { Number of Molecules in } \\
\text { the critical nucleus }\end{array}$} \\
\cline { 2 - 8 } & $\begin{array}{c}\text { Without } \\
\text { Additives }\end{array}$ & $\begin{array}{c}\text { With } \\
\text { SDS }\end{array}$ & $\begin{array}{c}\text { With } \\
\text { PEG }\end{array}$ & $\begin{array}{c}\text { Without } \\
\text { Additives }\end{array}$ & $\begin{array}{c}\text { With } \\
\text { SDS }\end{array}$ & $\begin{array}{c}\text { With } \\
\text { PEG }\end{array}$ \\
\hline 2.6 & 8.8 & 8.3 & 6.6 & 12 & 11 & 5 \\
\hline 3.0 & 7.6 & 7.3 & 5.7 & 8 & 7 & 4 \\
\hline 3.4 & 6.7 & 6.4 & 5.0 & 6 & 5 & 3 \\
\hline 4.3 & 5.8 & 5.4 & 4.3 & 4 & 3 & 2 \\
\hline
\end{tabular}

\section{Characterization of Strontium Malonate Apparatus and Instruments}

Strontium malonate precipitate is identified by X-ray diffraction (XRD) on a Brucker axis D8 diffractometer using $\mathrm{Cu} \mathrm{K \alpha}(\lambda=1.5406)$ radiation and secondary monochromator in the range $2 \theta$ from $5^{\circ}$ to $70^{\circ}$, CMRDI. The morphology of Strontium malonate particles is investigated by scanning electron microscope (SEM, JSM-5400), CMRDI. Thermal analysis of strontium malonate precipitate is made in the temperature range $10-1000^{\circ} \mathrm{C}$ with a heating rate of $10^{\circ} \mathrm{C} /$ minute using NETZSCH STA $409 \mathrm{C} / \mathrm{CD}$ apparatus under helium 
gas atmosphere, CMRDI. Chemical analysis and EDX analysis of strontium malonate crystals are made by Vario EL III Germany, Cairo Univ and scanning electron microscope (EDX, JSM-5400), CMRDI. Fourier Transmission Infra Red Spectrometer (FT-IR) of strontium malonate precipitate is made by JASCOJapan, Model 4100, Cairo Univ.

The primary nucleation of strontium malonate with and without additives was followed by conductivity measurement by using a Cond 315i/SET Conductimeter, CMRDI.

\section{XRD Analysis of Strontium Malonate}

Fig. (5) displays the XRD curves for strontium malonate crystals prepared at 4.3 supersaturation and prepared without and with additives. The results show that the XRD data is reasonable with the standard JCPDS file (file no. 31-1892). The results also show that sample prepared with SDS surfactant or PEG polymer has high peak intensity than without additives.

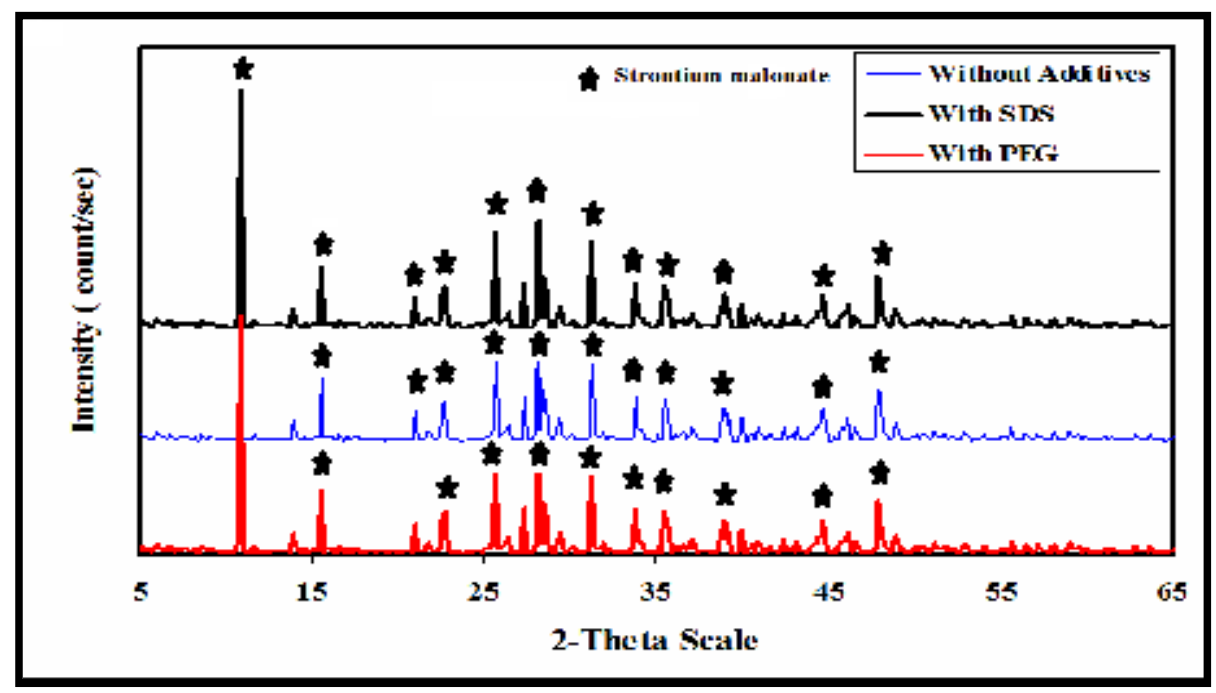

Fig. (5): XRD Pattern of Strontium Malonate with and without Additives.

\section{SEM Photomicrographs of Strontium Malonate}

SEM images of the strontium malonate crystals produced at supersaturation of 4.3 with and without additives are shown in Fig. (6). SEM investigation show that strontium malonate crystals have larger agglomerated particle size with SDS surfactant $(10-40 \mu \mathrm{m})$ compared to that of without additives $(5-20 \mu \mathrm{m})$. The reason for agglomerates formation is may be due to the decrees in induction time. Moreover, strontium malonate crystals have tabular 
structure of 2-20 $\mu \mathrm{m}$ diameter size with PEG polymer. The results of EDX and chemical analysis are carried out for the crystals and given in Fig. (7) and Table (5). The results show that there is a reasonable agreement between the obtained values experimentally using EDX and chemical analysis with that calculated chemical formula $\mathrm{SrC}_{3} \mathrm{H}_{2} \mathrm{O}_{4}$.
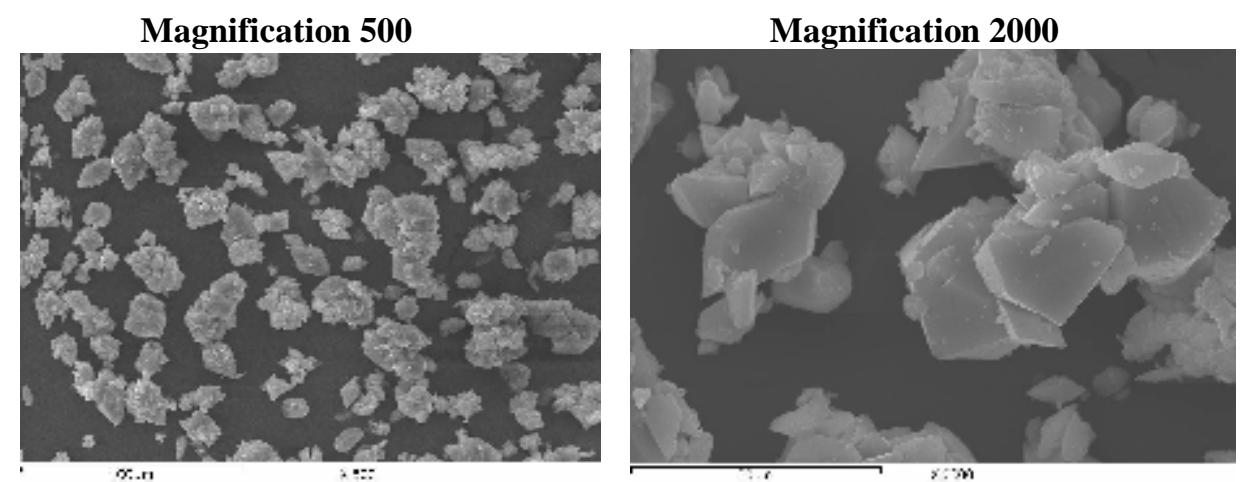

Without Additives

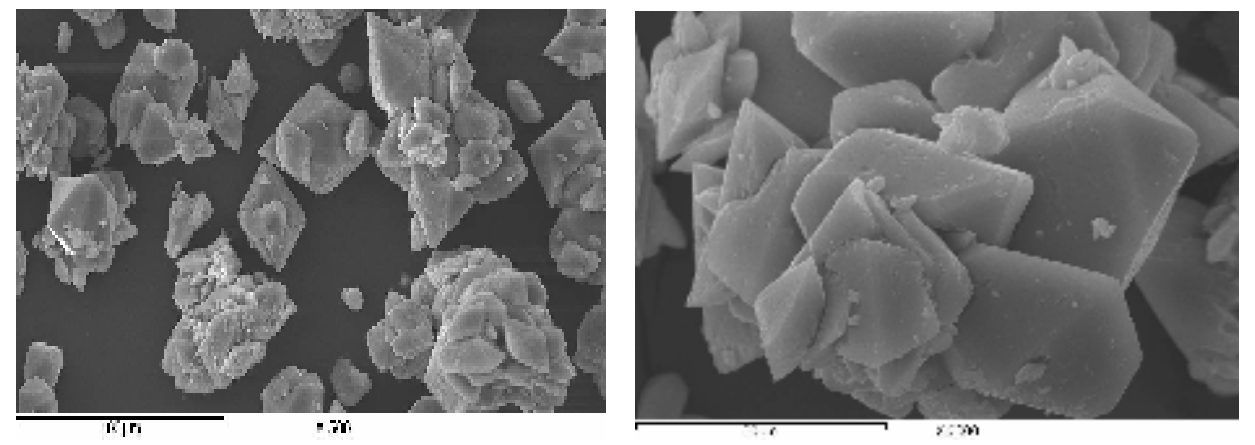

With SDS Surfactant
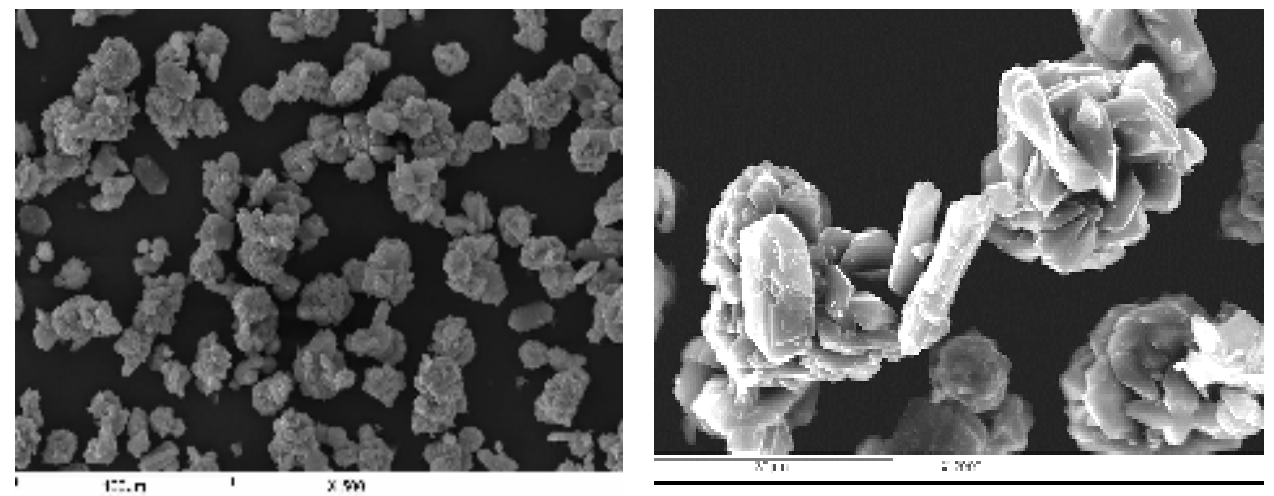

With PEG Polymer

Fig.(6): SEM Photomicrographs of Strontium Malonate without and with Additives at 4.3 Supersaturation and Different Magnifications 
Table (4): Assignment of Some Selected FT-IR Wave Numbers of Strontium Malonate.

\begin{tabular}{||c|c|c||}
\hline $\begin{array}{c}\text { IR, } \mathbf{~ c m}^{-1} \\
(\text { Strontium malonate })\end{array}$ & Assignment of peaks & $\begin{array}{c}\text { IR, } \mathbf{~ c m}^{-1} \\
(\text { Pure malonic acid })\end{array}$ \\
\hline 3013.2 & $\mathrm{v}(\mathrm{C}-\mathrm{H})$ & -- \\
1589.0 & $\mathrm{v}_{\text {as }}(\mathrm{C}=\mathrm{O})$ & $\mathbf{-})$ \\
$\mathbf{1 3 5 2 . 8}$ & $\mathrm{v}_{\mathrm{s}}(\mathrm{C}=\mathrm{O})$ & -- \\
947.8 & $\mathrm{v}(\mathrm{C}-\mathrm{C})$ & -- \\
\hline
\end{tabular}

Table (5): Chemical Composition of Strontium Malonate

\begin{tabular}{|c|c|c|c||}
\hline \hline Element & $\begin{array}{c}\text { EADX } \\
\text { Results }(\%)\end{array}$ & $\begin{array}{c}\text { Theoretical } \\
\text { Result }(\%)\end{array}$ & $\begin{array}{c}\text { C,H Chemical } \\
\text { Analysis (\%) }\end{array}$ \\
\hline C & 22.3 & 18.9 & 21.66 \\
\hline O & 31.5 & 33.7 & -- \\
\hline Sr & 46.2 & 46.2 & -- \\
\hline H & -- & 1.05 & 1.43 \\
\hline Total & 100.0 & 100.0 & -- \\
\hline
\end{tabular}

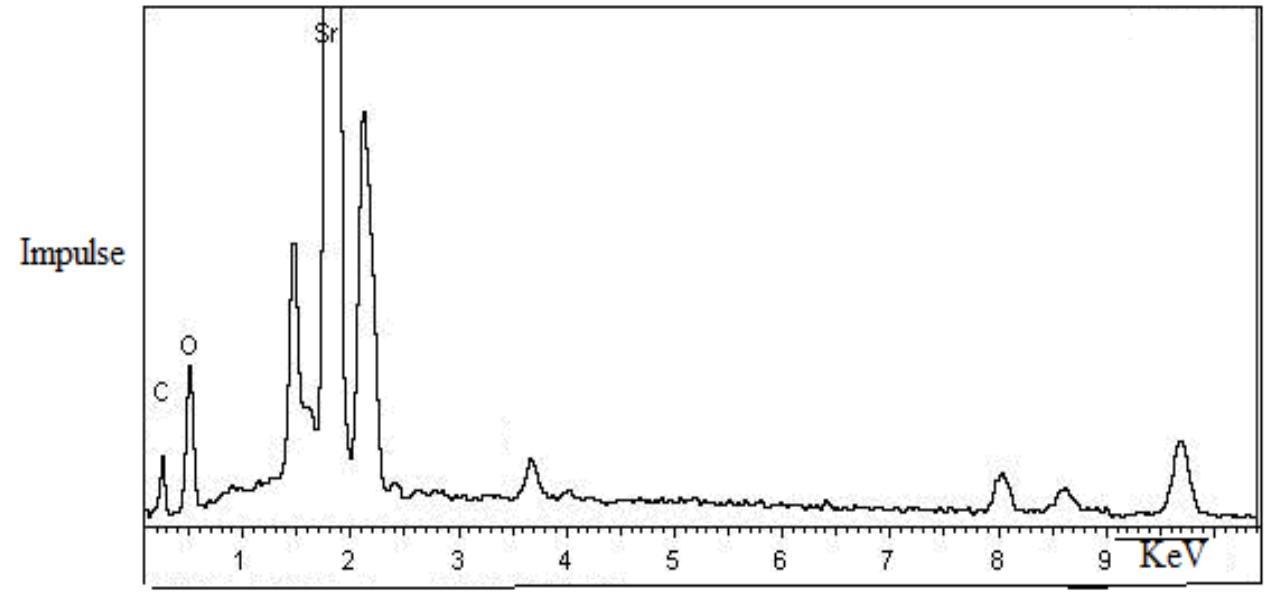

Fig. (7): EDAX Spectrum of Strontium Malonate

\section{TG and DTG Analysis of Strontium Malonate}

Thermal analysis of strontium malonate crystals were made in the temperature range $10-1000^{\circ} \mathrm{C}$. The decrease of weight by temperature is shown in the thermo gravimetric (TG) curve in Fig. (8), while the differential thermal gravimetric analysis (DTA) results are given in Fig. (8). From TG Curve, the total weight loss $\%$ or total mass change in the strontium malonate crystals is 
about $43.28 \%$. Moreover, the TG curve exhibits mass losses in two stages which indicate that the decomposition takes place continuously. It is seen that the TG curve shows a plateau up to $389^{\circ} \mathrm{C}$ suggesting that the compound is thermally stable up to a temperature of $389^{\circ} \mathrm{C}$. After this temperature, the curve describes a mass loss of $15.38 \%$ in the temperature range of 389-469. These results are in good agreement with published data of thermal decomposition of calcium malonate [17]. This mass loss is attributed to the decomposition of the sample to give $\mathrm{SrCO}_{3}$ as a residue by losing elements of the organic moiety in one step as calcium malonate [17]. The $\mathrm{SrCO}_{3}$ formed after decomposition remains stable up to $694^{\circ} \mathrm{C}$. In the temperature range of $694-934^{\circ} \mathrm{C}$, the TG curve shows a mass loss of $28.0 \%$. This stage indicates the thermal decomposition of the $\mathrm{SrCO}_{3}$ to strontium oxide $(\mathrm{SrO})$. The observed mass loss of $28.0 \%$ is in close agreement with the formation of $\mathrm{SrO}$ as the final product as calcium malonate [17].

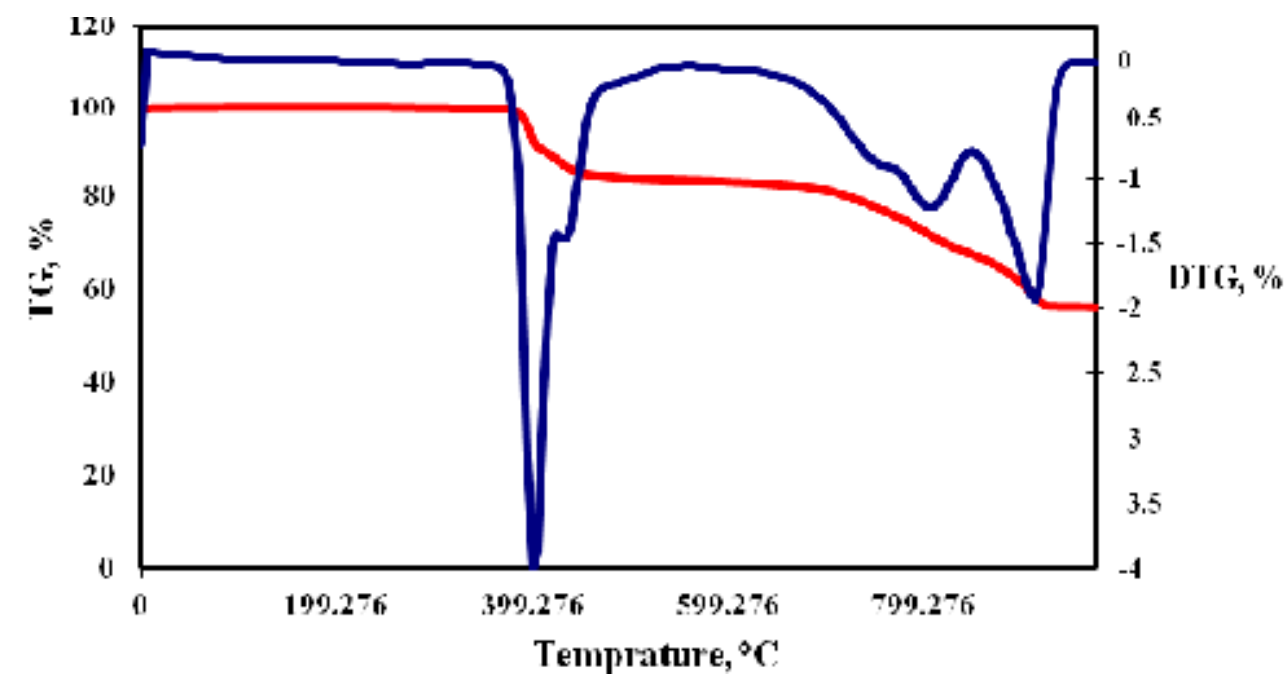

Fig. (8): TG and DTA Curve of Strontium Malonate

Weight loss observed in the all temperature regions $=43.28 \%$.

Weight of $\mathrm{SrO}=100-43.28=56.72 \%$

The following chemical reaction occurs during thermal treatment as calcium malonate [17].

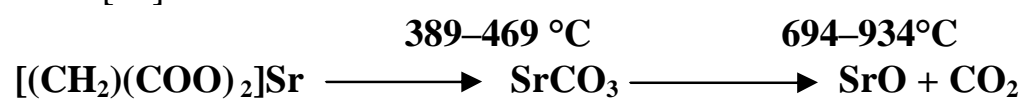

The DTA curve (Fig. 8) of strontium malonate showed two major peaks in the curve. The first peak corresponds to the endothermic decomposition of the malonate to $\mathrm{SrCO}_{3}$ at $400^{\circ} \mathrm{C}$. The second peak shows the decomposition of 
$\mathrm{SrCO}_{3}$ to $\mathrm{SrO}$ at temperature up to $919^{\circ} \mathrm{C}$. These results confirm that $\mathrm{SrCO}_{3}$ is the only residue left after the decomposition of strontium malonate as calcium malonate [17]. In addition, $\mathrm{SrO}$ is the only residue left after the decomposition of strontium carbonate.

\section{FT-IR spectrum of strontium malonate}

FT-IR spectrum of strontium malonate crystals is given in Fig. (9). In the range $400-4000 \mathrm{~cm}^{-1}$. The frequencies observed in the region of $3013-2310 \mathrm{~cm}^{1}$ are assigned to stretching vibration of $\mathrm{CH}$ group. The peaks appeared at 1589.06-1325 $\mathrm{cm}^{-1}$ are assigned to asymmetric (COO) $)_{\text {as }}$ stretch of coordinated carboxyl group and the absorption at $1352.8 \mathrm{~cm}^{-1}$ is due to $(\mathrm{COO})_{\mathrm{s}}$ symmetric vibration. The values of $\Delta \quad\left(\right.$ as $^{-} \quad$ s) for the material are $140 \mathrm{~cm}^{-1}$ and $237 \mathrm{~cm}^{1}$. These high values of $\Delta$ suggest bidentate chelating due to confinement of interaction with both oxygen atoms of caboxylate group. The peak of $(\mathrm{C}=\mathrm{O})$ of pure malonic acid appears at $1720 \mathrm{~cm}^{-1}[18]$. The $(\mathrm{C}=\mathrm{O})$ starching frequency has shifted from $1720 \mathrm{~cm}^{-1}$ to $1589 \mathrm{~cm}^{-1}$. The value of $\Delta$ ( free ${ }^{-}$complex $)$is 131 $\mathrm{cm}^{1}$. The frequency shifted to lower frequency by $131 \mathrm{~cm}^{-1}$ due to the oxygen atom of carboxyl group has coordinated with $\mathrm{Sr}^{2+}[18]$. The obtained spectrum of strontium malonate crystals (Fig. 9) shows a strong peak at $1165.76 \mathrm{~cm}^{1}$ due to the asymmetric vibration (C-C) as and another strong peak at $947.84 \mathrm{~cm}^{-1}$ due to the symmetric vibration of $(\mathrm{C}-\mathrm{C})_{\mathrm{s}}$. Thus IR spectrum of strontium malonate confirms the presence of malonate ligands [19]. The assignment of some selected absorption bands/peaks as observed in FT-IR spectrum is shown in Table (4).

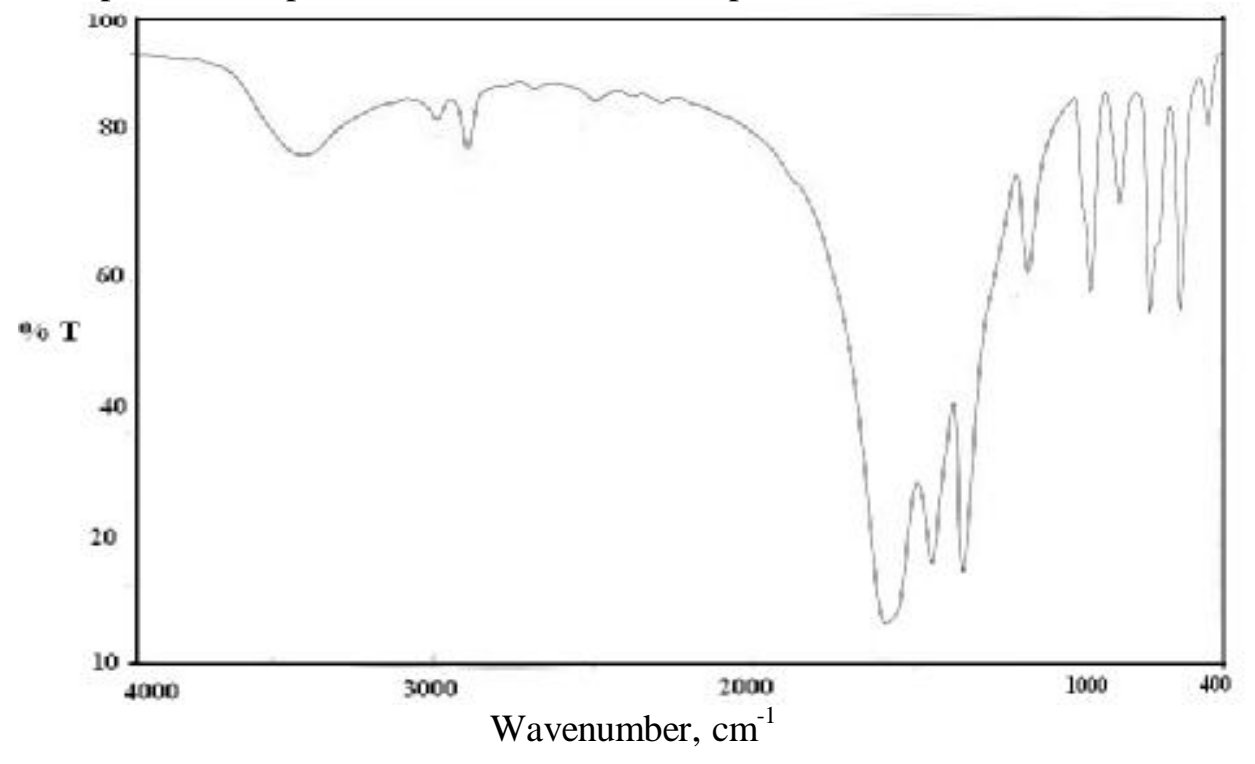

Fig. (9): FT-IR Spectrum of Strontium Malonate 


\section{Conclusions:}

Crystallization of strontium malonate without and with additives such as sodium dodecyl sulfate (SDS) surfactant and poly ethylene glycol (PEG) polymer are studied. The results indicate that:

- SDS or PEG decrease the induction time at all the supersaturations studied due to decreases the regular crystal growth.

- Surface energy is decreased in the presence of SDS or PEG compared with the baseline.

- Nucleation rate is increased in the presence of SDS or PEG compared with the baseline.

- The Critical nucleus diameter and hence size is smaller in the presence of SDS or PEG.

- Crystalline size is smaller in the presence of SDS or PEG.

\section{References:}

1. Stephan Christgau ands Jens E.T. Andersen; High Yield Synthesis Methods for Producing Organic Salts of Strontium, US Patent No. 0137678 A1, (2009).

2. H. El-Shall, E.A. Abdel-Aal and B. Moudgil; Effect of Surfactants on Phosphogypsum Crystallization and Filtration during Wet-Process Phosphoric Acid Production, Separation Science and Technology Journal, 35, 395 (2000).

3. H. El-Shall, M.M. Rashad, E.A. Abdel-Aal; Effect of phosphonate additive on crystallization of gypsum in phosphoric and sulfuric acid medium, Crystal Research Technology Journal, 37, 1264 (2002).

4. M.M. Rashad, H.M. Baioumy, and E.A. Abdel-Aal; Structural and spectral studies on gypsum crystals under simulated conditions of phosphoric acid production with and without organic and inorganic additives, Crystal Research Technology Journal, 38, 433 (2003).

5. M.H. Mahmoud, M.M. Rashad, I.A. Ibrahim, and E.A. Abdel-Aal; Crystal Modification of Calcium Sulfate Dihydrate in the Presence of some SurfaceActive Agents, J. Colloid and Interface Science, 270, 99 (2004).

6. M. M. Rashad, M.H.H. Mahmoud, I.A. Ibrahim, and E.A. Abdel-Aal; Effect of Citric Acid and 1,2-dihydroxybenzene 3,5-disulfonic Acid on Crystallization of Calcium Sulfate Dihydrate under Simulated Conditions of Phosphoric Acid Production, Cryst. Res. Technol, 40, 739 (2005).

7. H. El-Shall, M. M. Rashad, and E. A. Abdel-Aal; Effect of Cetyl Pyridinium Additive on Crystallization of Gypsum in Phosphoric and Sulfuric Acids Medium, Cryst. Res. Technol, 40, 860 (2005). 
8. E.A. Abdel-Aal, M.H.H. Mahmoud, H. El-Shall, A.K. Ismail; Increasing the filtration rate of phosphor-gypsum using surfactant, Hydrometallurgy, 85, 53 (2007).

9. N. S. Tavare; Industrial Crystallization: Process Simulation Analysis and Design.The Plenum Chemical Engineering Series, New York (1995).

10. Stephan Christgau and Jens E.T. Andersen; water- soluble strontium salts for use in treatment of cartilage and/or bone condition. US Patent No. 7595342, B2, (2009).

11. S. He, J. E. Oddo, M. B. Tomson; The inhabitation of gypsum and barite nucleation in $\mathrm{NaCl}$ brines at temperatures from 25 to $90^{\circ} \mathrm{C}, \mathrm{J}$. Appl. Geochem, 9, 561 (1994).

12. A. Lancia, D. Musmara, and M. Prisciandaro; Measuring induction period for calcium sulfate dehydrate preciptation, J. AIChE, 45, 390 (1999).

13. A. S. Myerson; "Handbook Industrial crystallization.ButterworthHeinemann", Boston, USA, (1993).

14. D. A. Randolph and A. M. Larson; Theory of Particulate Processes: Analysis and Techniques of Continuous Crystallization, $2^{\text {nd }}$. Ed. San Diego, USA, (1988) p.114.

15. J. Nyvlt and J. Ulrich; Admixtures in Crystallization, ch.2.VCH, Weinheim, (1995).

16. S. Boomadevi, R. Dhanasekaran, and P. Ramasamy; Investigation on nucleation and growth kinetics of urea crystals from methanol, Cryst. Res. Technol, 37, 156 (2002).

17. K.C. Patil, G .V. Chandrashekhma, R.V. George, C.N.R. Rao; Infrared spectra and thermal decompositions of metal acetates and dicarboxylates, Canadian journal of chemistry, 46, 258 (1968).

18. A. Jayashree, F. Rajammal Selvarani, J. Wilson Sahayaraj, A. John Amalraj, S. Rajendran; Malonic Acid as Transporter of $\mathrm{Zn}^{2+}$ Towards Carbon Steel Surface, Portugaliae Electrochimica Acta, 27, 23 (2009).

19. Varghese Mathew, Jochan Joseph, Sabu Jacob and K. E. Abraham; Spectroscopic characterization of gel grown strontium malonate crystals, Indian Journal of pure and applied arts, 49, 21 (2011). 